\title{
The waiting game - the Canadian Association of Gastroenterology calls on the Canadian Medical Association to open up the Wait Times Initiative
}

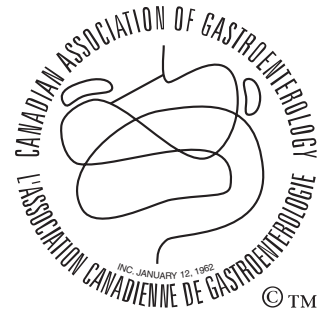

En français voir page 739

Desmond Leddin MB FRCPC

President, Canadian Association of Gastroenterology

Professor and Head, Division of Gastroenterology, Dalhousie University, and

Service Chief, Gastroenterology, Capital District Health Authority

$\mathrm{T}$ he Canadian Association of Gastroenterology (CAG) has called on the Canadian Medical Association (CMA) and Federal Health Minister Ujjal Dosanjh to open up the Wait Times Initiative to all groups who have established benchmarks for wait times.

Waiting times for health care are a concern for both health care users and providers. The federal and provincial governments moved to address this by targeting five areas: cancer, cardiac care, diagnostic imaging, sight restoration and joint replacement. The plan was to develop benchmarks for wait times in the five priority areas by the end of 2005 and to achieve significant reductions in wait times by March 31, 2007.

The rationale behind choosing the five selected areas is not clear. These conditions are certainly common, a cause of significant morbidity and mortality, and a significant economic burden. In addition, some of them (eg, cataract surgery) also have the benefit of having an easily defined, measurable outcome. On the other hand, who is to say that Crohn's disease is less deserving of attention than cardiac disease? Is it a coincidence that these conditions predominantly affect the older, voting public and that there is no mention of childhood illnesses?

In response to the government initiative, seven physician groups formed the Wait Time Alliance (WTA). With the financial support of the federal government, they set about establishing benchmarks for access to care in their areas. The groups in the WTA are the Canadian Association of Nuclear Medicine, the Canadian Association of Radiologists, the Canadian Association of Radiation Oncologists, the CMA, the Canadian Cardiovascular Society, the Canadian Ophthalmologic Society and the Canadian Orthopedic
Society. Dr Ruth Collins-Nakai, who is also the current president of the CMA, chairs the Alliance.

The WTA issued its final report in August 2005. The report makes a number of recommendations, many of which are in the interests of all patients and all physician advocacy groups not just of the Alliance member groups.

The federal and provincial government response to the report has been subdued. It appears likely that government will not meet its deadline of December 31, 2005, for the establishment of benchmarks in the selected areas.

The CAG met with Department of Health officials in Ottawa, Ontario, last year to raise concerns about wait times in gastroenterology (GI). The response was polite, but no support for measurement of wait times in GI was forthcoming. However, the CAG, under the leadership of the incoming president Dr Bill Paterson, has been able to define evidencebased maximal wait times in key areas of GI (awaiting publication). In addition, through the Practice Audit in Gastroenterology (PAGE) program, we have measured actual wait times for over 5500 clinic and endoscopy visits. The comparison of desirable versus actual wait times in GI paints a worrisome picture. In general, benchmark wait times are achieved only $20 \%$ of the time and, in some areas, the results are worse. Patients with symptoms highly suggestive of inflammatory bowel disease are seen in an appropriate time in only $4 \%$ of referrals.

The national data were released at the World Congress of Gastroenterology meeting in Montreal, Quebec, this past September. The data are currently being analyzed by province and the results will be available for presentation at Canadian

The CAG is proud to acknowledge its Benefactor Corporate Sponsors:
Abbott Laboratories Ltd
AstraZeneca Canada Inc
Axcan Pharma Inc
Janssen-Ortho Inc
Pfizer Canada Inc
Schering Canada Inc 
Digestive Diseases Week in Banff, Alberta, February 24-27, 2006.

The national data are of such concern that the CAG has written to the chair of the CMA and to the Federal Minister of Health asking that the WTA be opened up to include groups who have benchmarks ready for implementation.

It is vital that the federal and provincial governments and the CMA take a broader view of access to health care than just that of the selected five areas for two reasons.

First, there are many other areas of health care that are as vital as those that have been selected.

Second, consider what may happen if the government actually responds to the WTA recommendations. Benchmarks are now in place for at least some aspects of the selected five areas. The process behind this was supported by the federal government, which can hardly, therefore, disown the results. What will happen if the actual wait times are measured in these areas and found to be outside the acceptable range? It is likely that resources will be deployed to move actual wait times closer to benchmarks so that the government can say that progress is being made in addressing access concerns. Will these be new resources or reallocation of existing resources? Given past government performance, it is likely to be the latter scenario. Either way, there is a real possibility of making a bad situation worse in GI and many other nonprioritized areas of medicine.

Advocacy on behalf of gastroenterologists and on behalf of patients with gastrointestinal diseases has emerged as a key part of CAG activity. Working in close conjunction with our provincial GI Associations, we will succeed in moving this forward. 


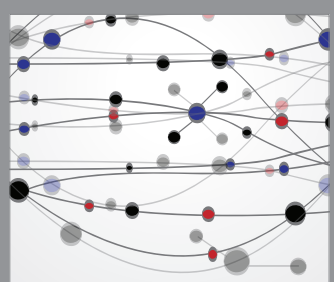

The Scientific World Journal
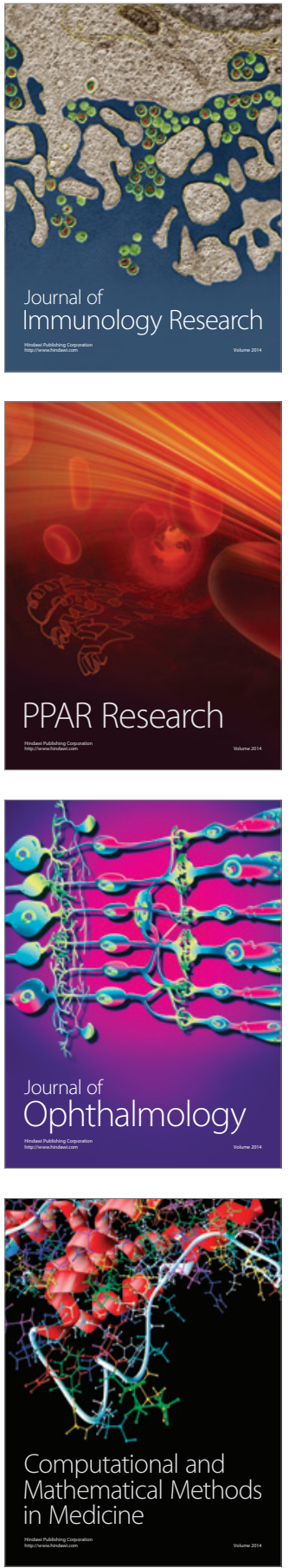

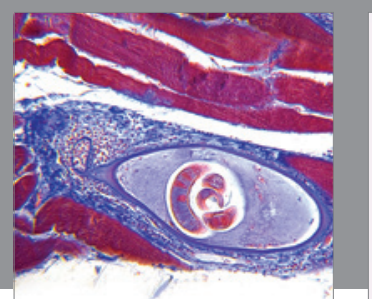

Gastroenterology Research and Practice

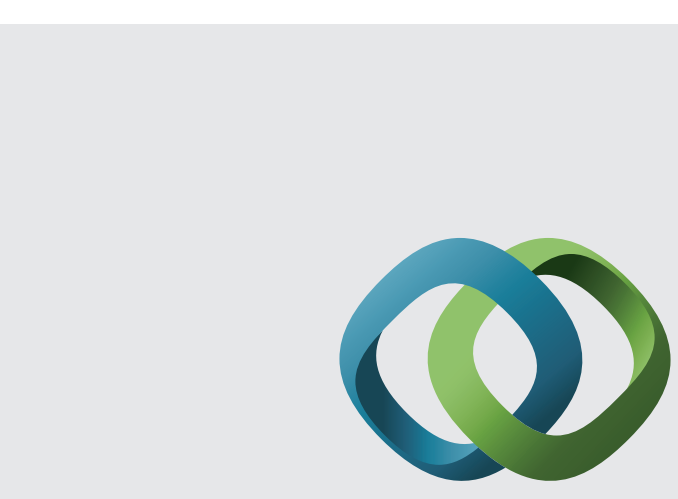

\section{Hindawi}

Submit your manuscripts at

http://www.hindawi.com
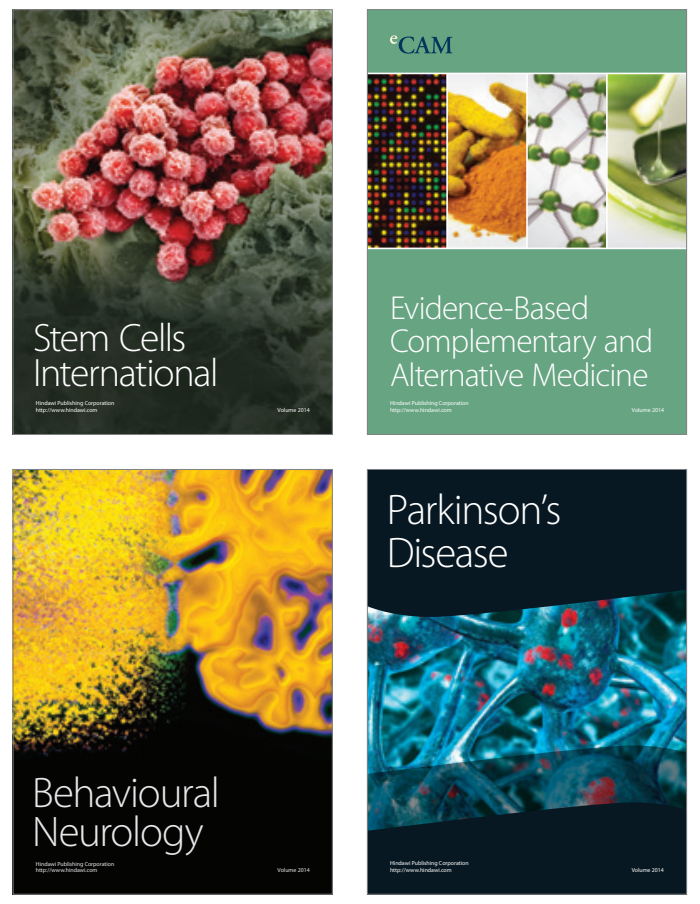
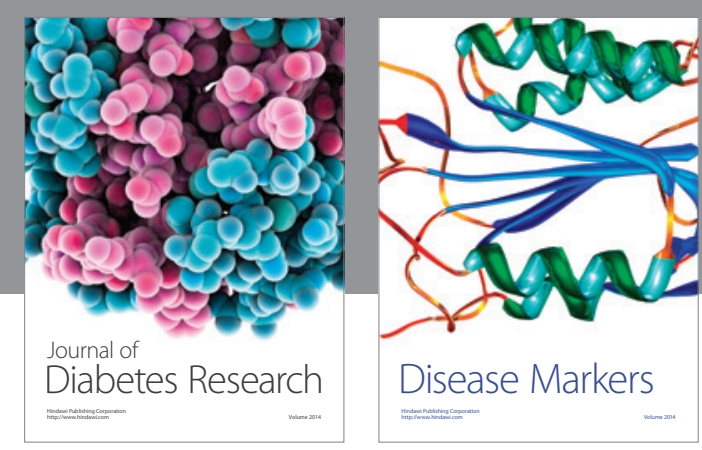

Disease Markers
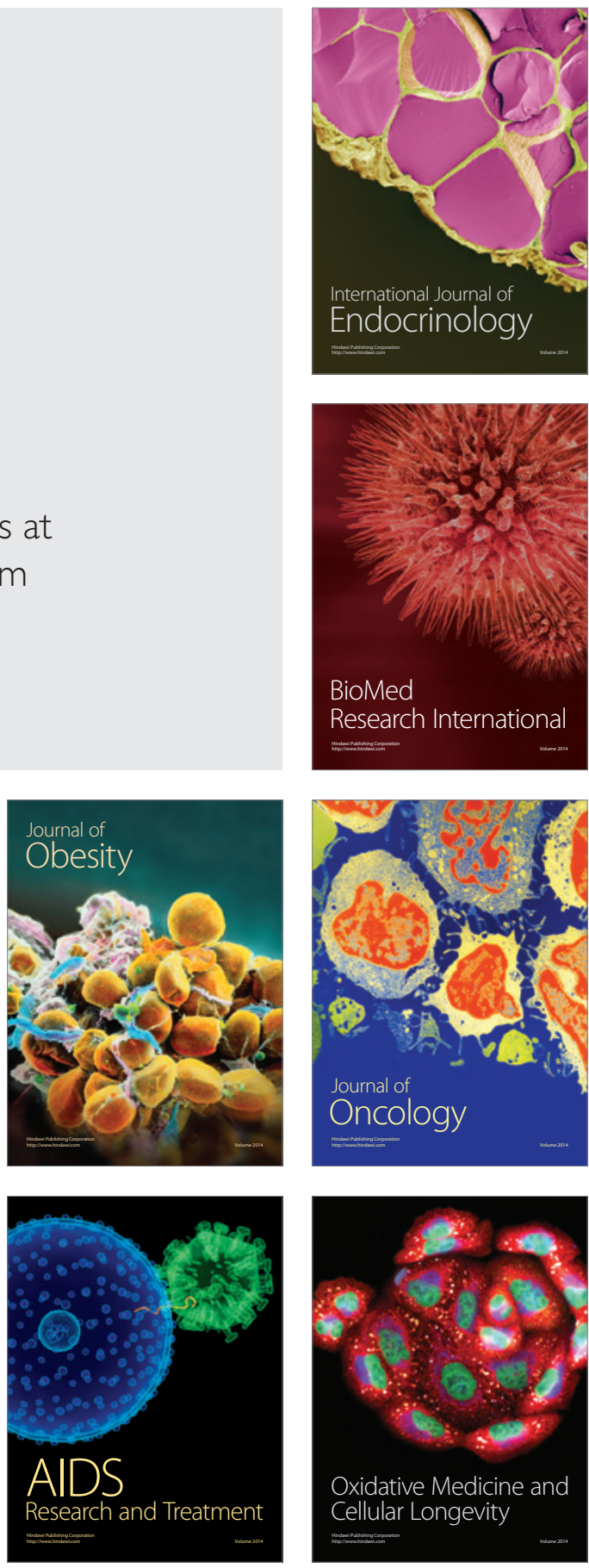